\title{
Foraging areas of Magellanic penguins Spheniscus magellanicus breeding at San Lorenzo, Argentina, during the incubation period
}

\author{
Rory P. Wilson ${ }^{1, *}$, J. Alejandro Scolaro ${ }^{2}$, Gerrit Peters ${ }^{1}$, Sonja Laurenti ${ }^{2}$, \\ Mandy Kierspel ${ }^{1}$, Héctor Gallelli ${ }^{2}$, Jorge Upton ${ }^{2}$ \\ ${ }^{1}$ Institut für Meereskunde, Düsternbrooker Weg 20, D-24105 Kiel, Germany \\ ${ }^{2}$ Centro Nacional Patagonico, Boulevard Brown s/n, 9120 Puerto Madryn, Chubut, Argentina
}

\begin{abstract}
During October 1994, 10 miniature global location sensors were attached to Magellanic penguins before they departed to sea to forage while their mates remained at the nest incubating. The devices indicated that birds swam a mean distance of $70.4 \mathrm{~km}$ (SD 42.1) on the first and last days of the foraging trips, thus distancing themselves rapidly from the colony. On other days the mean distance swum was $50.2 \mathrm{~km}$ (SD 31.4, mode 35). Maximum distance from the colony during the foraging trip by any bird was $303 \mathrm{~km}$, but highest bird densities occurred at a point $120 \mathrm{~km}$ east of the colony and coincided with the presence of a front.
\end{abstract}

KEY WORDS: Magellanic penguin · Global location · At sea distribution · Foraging

\section{INTRODUCTION}

Breeding seabirds are central place foragers (Orians \& Pearson 1979), having to return to their nests between foraging bouts. The maximum foraging range is dictated by the frequency with which foraging birds must return to the nest. Frequency is a function of brood energy requirements and travelling speed (Pearson 1968). The actual foraging range however, may be considerably less (e.g. Weimerskirch et al. 1988), and is most likely to be determined by prey distribution (cf. Hunt et al. 1986). Prey distribution may, in turn, be affected by predation pressure exerted by the seabirds. There is evidence (Birt et al. 1987) to suggest that cormorants exert enough predator pressure to locally deplete prey resources adjacent to breeding colonies. It has been hypothesized (Birt et al. 1987) that birds which travel further from the colony experience better fishing conditions than those that forage close to the colony. To optimize energy, seabirds should balance travelling costs to the foraging site with

•E-mail: rwilson@ifm.uni-kiel.de costs incurred during prey searching. The extent to which this might actually occur could be assessed by examining the foraging localities of breeding seabirds under different foraging duration constraints because ultimately, if time permitted, birds could travel so far away from the colony that intra-specific competition becomes negligible. This is often assumed to be the situation during the non-breeding season.

The Magellanic penguin Spheniscus magellanicus is an excellent bird in which to study this problem. It occurs in large colonies comprising at least 400000 birds (Scolaro 1986, Boersma et al. 1990) but, like all penguins, during the breeding season it has a particularly limited foraging range resulting from flightlessness. Over the course of the breeding cycle, the Magellanic penguin has a highly variable foraging trip duration. After the clutch is laid one bird remains incubating the eggs for a period which may exceed $3 \mathrm{wk}$ while the partner incubates the eggs. When the foraging bird returns to the nest, roles change so that the previously incubating bird spends an extended spell at sea. Incubating/foraging shifts then become progressively shorter until the eggs hatch (Scolaro 1984, Yorio 
\& Boersma 1994). While tending chicks foraging trips rarely last longer than $2 \mathrm{~d}$ (Scolaro 1986).

We examined the foraging location of Magellanic penguins during the incubation phase of the breeding cycle and compared it to calculated foraging ranges of birds tending chicks. We hypothesized that no differences in foraging range between the 2 periods would indicate that intra-specific competition was unimportant in Magellanic penguins and that the pelagic nature of their prey meant that prey depletion did not occur. Different distributions between the 2 periods might indicate otherwise

\section{MATERIALS AND METHODS}

Field work was carried out at the Magellanic penguin colony estimated to consist of some 40000 birds at Estancia San Lorenzo ( $42^{\circ} 04^{\prime} \mathrm{S}, 63^{\circ} 37^{\prime}$ E), Peninsula Valdes, Chubut, Argentina, between September and December 1994. On 14 October, 10 birds incubating eggs were caught and fitted with Global Location Sensors (GLSs) which were attached to the lower back (dorsal midline - following suggestions made by Bannasch et al. 1994) with 2-component neoprene glue (Deutsche Schlauchbootfabrik, Eschershausen, Germany) and Tesa tape (Wilson \& Wilson 1989). Birds were measured so that they could be sexed (Scolaro et a1. 1983) and released back at the nest so that they could resume incubating. Birds were then left to go to sea before checks were then made for recovered birds on 14 and 18 November as well as daily between 21 November and 16 December. When birds with GLSs were recovered the devices were removed before stored data were downloaded.

Each GLS consisted of a logger (the 'pillbox' logger; Driesen \& Kern GmbH, D-24576 Bad Bramstedt, Germany) with a 128 kbyte memory, which recorded data on ambient light intensity at intervals of $128 \mathrm{~s}$. Light intensity data were only recorded between 0 and approximately 25 lux (all values in excess of this were recorded as 25 lux) with an 8-bit resolution. The photo sensor in the unit was covered by a blue filter so as to record light least sensitive to cloud cover. The GLS was driven by two $3 \mathrm{~V}$ DL1/3N lithium batteries and, to make the apparatus watertight, the complete unit was encased in resin bounded by a blown glass cover ca $0.5 \mathrm{~mm}$ thick. The streamlined device weighed $42 \mathrm{~g}$ and had maximum dimensions of $125 \times 38 \times 25 \mathrm{~mm}$. Data on ambient light intensity from GLSs together with knowledge of the exact time (Greenwich Mean Time) and date can be used to calculate the position of the device because the times of dawn and dusk are a unique function of date and locality, except for a few days around the equinox (Wilson et al. 1992, Hill 1993,
R. P. Wilson, W. G. Rees, J. Lage, K. Pütz, M. A. Kierspel, J. Cooper, C. A. Bost, J. A. Scolaro \& B. Culik unpubl.).

All GLSs were calibrated at known positions in Argentina for a minimum of $5 \mathrm{~d}$ to determine the threshold values corresponding to dawn and dusk to be used in location estimations. These thresholds were determined for sun elevation angles of -0.095 rads, as they were to be used for the at-sea data. After recovering the GLSs from the birds the data were analyzed using the program LOCATE (version 2.0-Jensen Software, D-77694 Kehl, Germany). LOCATE incorporates a number of features which enhance the accuracy of location estimations. This includes correction for extensive movement by device-carrying animals between any consecutive dawn and dusk, a smoothing option to reduce out-lying fixes and the adjacent replacement' option for diving animals. This option is useful for animals that often dive around dawn and dusk. Since the GLSs record data at set intervals, some recordings occur when the animals are underwater where ambient light intensity is lower than at the surface. Thus, around dawn and dusk, diving animals may show a change in light intensity that is not smooth because it consists of relatively high readings made when the animals are at the surface interspaced with lower readings made when the animals are underwater. Since the GLS-carrying animals cannot record more light than there is at the surface, the highest values define specific points in what would normally be the change in light intensity at the surface. In the 'adjacent replacement' option, the user can temporarily store smooth changes in light intensity around dawn and dusk, either from periods when the animals were not diving or from calibrations, and use them to replace periods around dawn and dusk when the animals are diving. In this case the new curves are moved into place so that the highest point in the curve from the diving period coincides with the replacement curve. This option has been shown to reduce substantially errors in location estimates incurred due to the diving (Wilson et al. unpubl. data). In addition, the quality of fixes can be classified according to the smoothness of the changes in light intensity around dawn and dusk. The accuracy of positional fixes is estimated to be within $40 \mathrm{~km}$ for class 1 fixes and within $150 \mathrm{~km}$ for class 5 fixes (Wilson et al. unpubl. data). Mean error in position determinations of the GLSs during calibrations on land was $33.9 \mathrm{~km}$ (SD 16.6, $\mathrm{n}=52$ ). We are unable to give a precise estimation of the additional errors incurred due to changes in light intensity at dawn and dusk as the penguins dived. However, information derived from king penguins Aptenodytes patagonicus suggests that these errors do not exceed $70 \mathrm{~km}$ (K. Pütz unpubl. data) 


\section{RESULTS}

All 10 of the devices deployed were recovered after a mean deployment period of $37.4 \mathrm{~d}$ (SD 7.6, range 31 to 58). Eight of the birds to which the GLSs were fixed continued to breed in an apparently normal manner for at least the first $3 \mathrm{wk}$ while 2 birds deserted their nests, although both were recovered in their nest after 41 and $58 \mathrm{~d}$, respectively. Overall, however, only 5 of

Table. 1. Presence/absence chart of GLS-equipped Magellanic penguins at Punta Norte. B: bird in burrows; $X$ : bird at sea; - device malfunction

\begin{tabular}{|c|c|c|c|c|c|c|c|c|c|c|}
\hline Bird no.. & 1 & 2 & 3 & 4 & 5 & 6 & 7 & 8 & 9 & 10 \\
\hline Mass $(\mathrm{kg})$ : & 3.3 & 3.2 & 3 & 3.1 & 4.7 & 3.2 & 3.5 & 3.8 & 5.3 & 2.7 \\
\hline Sex: & F & $\mathrm{F}$ & F & $\mathrm{F}$ & $M$ & $\mathrm{~F}$ & $\mathrm{~F}$ & $F$ & $M$ & $\mathrm{~F}$ \\
\hline 18 Oct & B & B & B & B & B & B & B & B & B & • \\
\hline 19 Oct & $B$ & B & B & B & B & B & B & B & B & • \\
\hline 20 Oct & B & B & B & B & B & B & B & B & B & • \\
\hline 21 Oct & B & $x$ & B & $B$ & B & B & B & B & $\mathrm{B}$ & • \\
\hline 22 Oct & $x$ & $\mathrm{X}$ & B & B & B & B & $x$ & B & B & - \\
\hline 23 Oct & $x$ & $x$ & B & $\mathrm{X}$ & B & B & $\mathrm{X}$ & $\mathrm{X}$ & B & • \\
\hline 24 Oct & $x$ & $x$ & $x$ & $x$ & $x$ & B & $\mathrm{X}$ & $\mathrm{X}$ & B & • \\
\hline $25 \mathrm{Oct}$ & $x$ & $x$ & $\mathrm{X}$ & $\mathrm{x}$ & $B$ & B & $x$ & $\mathrm{X}$ & B & - \\
\hline $26 \mathrm{Oct}$ & $\mathrm{X}$ & $\mathrm{x}$ & $x$ & $\mathrm{x}$ & B & B & $\mathrm{X}$ & $\mathrm{X}$ & B & $\cdot$ \\
\hline 27 Oct & $x$ & $x$ & $x$ & $x$ & $x$ & $B$ & $x$ & $X$ & B & • \\
\hline 28 Oct. & $\mathrm{X}$ & $\mathrm{X}$ & $x$ & $\mathrm{X}$ & B & $\mathrm{X}$ & $x$ & $x$ & $\mathrm{X}$ & $\cdot$ \\
\hline $29 \mathrm{Oct}$ & $x$ & $x$ & $x$ & $x$ & $B$ & $B$ & $x$ & $\mathrm{X}$ & $X$ & $\cdot$ \\
\hline 30 Oct & $x$ & $x$ & $x$ & $x$ & $B$ & $X$ & $x$ & $\mathrm{~B}$ & $x$ & $\cdot$ \\
\hline $31 \mathrm{Oct}$ & $x$ & $X$ & $x$ & $x$ & $B$ & $B$ & $x$ & $\mathrm{~B}$ & $x$ & $\cdot$ \\
\hline 1 Nov & $x$ & $B$ & $x$ & $x$ & $X$ & $x$ & $x$ & $\mathrm{~B}$ & $x$ & $\cdot$ \\
\hline $2 \mathrm{Nov}$ & $x$ & $B$ & $x$ & $x$ & $\mathrm{X}$ & $x$ & $x$ & $\mathrm{~B}$ & $\mathrm{X}$ & $\cdot$ \\
\hline 3 Nov & $x$ & B & $x$ & $x$ & $x$ & $x$ & $x$ & $x$ & $X$ & $\cdot$ \\
\hline $4 \mathrm{Nov}$ & $x$ & $B$ & $X$ & $x$ & $x$ & $X$ & $\mathrm{X}$ & $x$ & B & $\cdot$ \\
\hline $5 \mathrm{Nov}$ & $x$ & B & $x$ & $x$ & $x$ & $X$ & $x$ & $x$ & $\mathrm{~B}$ & $\cdot$ \\
\hline $6 \mathrm{Nov}$ & $x$ & $x$ & $x$ & $X$ & $x$ & $x$ & $x$ & $X$ & $\mathrm{~B}$ & $\cdot$ \\
\hline 7 Nov & $x$ & $X$ & $\mathrm{X}$ & $X$ & $x$ & $x$ & $\mathrm{X}$ & $x$ & $\mathrm{~B}$ & $\cdot$ \\
\hline 8 Nov & $x$ & $x$ & $x$ & $x$ & $x$ & $X$ & $x$ & $x$ & $x$ & $\cdot$ \\
\hline 9 Nov & $x$ & $x$ & $x$ & $x$ & $x$ & $x$ & $x$ & $X$ & $B$ & $\cdot$ \\
\hline 10 Nov & $x$ & $x$ & $x$ & $x$ & B & $x$ & $\mathrm{X}$ & $X$ & $x$ & $\cdot$ \\
\hline $11 \mathrm{Nov}$ & $B$ & $x$ & $x$ & $\mathrm{X}$ & $x$ & $x$ & $x$ & $X$ & $x$ & $\cdot$ \\
\hline 12 Nov & B & B & $x$ & $X$ & $\mathrm{X}$ & $x$ & $x$ & $x$ & $\mathrm{X}$ & $\cdot$ \\
\hline 13 Nov & $\mathrm{x}$ & $\mathrm{X}$ & $x$ & $B$ & $x$ & $x$ & $x$ & $X$ & B & - \\
\hline 14 Nov & B & $x$ & $x$ & $B$ & $x$ & $x$ & $x$ & $\mathrm{X}$ & $x$ & - \\
\hline $15 \mathrm{Nov}$ & $x$ & $x$ & $x$ & $\mathrm{~B}$ & $x$ & $x$ & $x$ & $x$ & $B$ & $\cdot$ \\
\hline 16 Nov & $\mathrm{x}$ & $B$ & B & $\mathrm{B}$ & $x$ & $x$ & $x$ & $B$ & $B$ & $\mathrm{x}$ \\
\hline 17 Nov & $B$ & $x$ & B & $\mathrm{B}$ & $X$ & $x$ & $x$ & $X$ & $x$ & $x$ \\
\hline 18 Nov & $x$ & $x$ & B & $B$ & $x$ & $x$ & $x$ & $x$ & $B$ & $\mathrm{X}$ \\
\hline 19 Nov & $\mathrm{X}$ & $\mathrm{B}$ & & & $x$ & $x$ & $X$ & $X$ & & $\mathrm{X}$ \\
\hline $20 \mathrm{Nov}$ & $B$ & $x$ & & & $x$ & $X$ & $X$ & $x$ & & $x$ \\
\hline $21 \mathrm{Nov}$ & $\mathrm{X}$ & $X$ & & & $\mathrm{x}$ & $x$ & $x$ & $x$ & & $\mathrm{X}$ \\
\hline $22 \mathrm{Nov}$ & B & B & & & $x$ & $B$ & $x$ & $X$ & & $x$ \\
\hline $23 \mathrm{Nov}$ & & & & & $x$ & & $x$ & $x$ & & $\mathrm{X}$ \\
\hline 24 Nov & & & & & $x$ & & $x$ & $x$ & & $x$ \\
\hline 25 Nov & & & & & & & $x$ & $x$ & & $X$ \\
\hline 26 Nov & & & & & & & $x$ & $x$ & & $x$ \\
\hline 27 Nov & & & & & & & $x$ & & & $x$ \\
\hline$\downarrow$ & & & & & & & $\downarrow$ & & & \\
\hline $15 \mathrm{Dec}$ & & & & & & & $\mathrm{X}$ & & & \\
\hline $16 \mathrm{Dec}$ & & & & & & & $x$ & & & \\
\hline
\end{tabular}

the 10 nests where birds were equipped with GLSs had healthy chicks at the time the devices were removed. Unfortunately, we did not document breeding success in nests containing unequipped birds so we have no means of assessing the degree to which breeding failures were due to our devices or handling. Yorio \& Boersma (1994) report that rates of nest desertion in the Magellanic penguin during incubation are of the order of $11 \%$ (range 3 to $30 \%$ ). Hatching success, however, which incorporates egg losses due to predation etc. as well as desertion, varies between 32 and $80 \%$ (for summary see Williams 1995) while overall breeding success varies between 1 and $55 \%$ (Boersma 1988).

Periods when the birds were present in the breeding burrows and when they were at sea were very clear from the recordings of light intensity stored by the GLSs because the reduced light levels in the burrows compared to those outside extend the time over which the measured light intensity changes from around 0 to 25 lux by a factor of ca 4 . The 8 birds that continued breeding normally after attachment of the units spent a mean of $5.9 \mathrm{~d}$ in their burrows before going to sea ( $\mathrm{SD}$ 2.2 , range 3 to 9.5 ), followed by a mean period at sea of $16.1 \mathrm{~d}$ ( $\mathrm{SD}$ 8.2, range 3 to 24). Although 5 individuals spent extended periods at sea, other birds went to sea for much shorter periods over multiple trips (Table 1) The 2 birds that ultimately deserted their nests spent 3.5 and $4.5 \mathrm{~d}$ in their burrows, respectively, before going to sea for 55.5 and 7 d respectively (Table 1).

Foraging trips typically followed a looping course (Fig. 1) where birds left the colony heading in a particular direction before arriving at a particular point

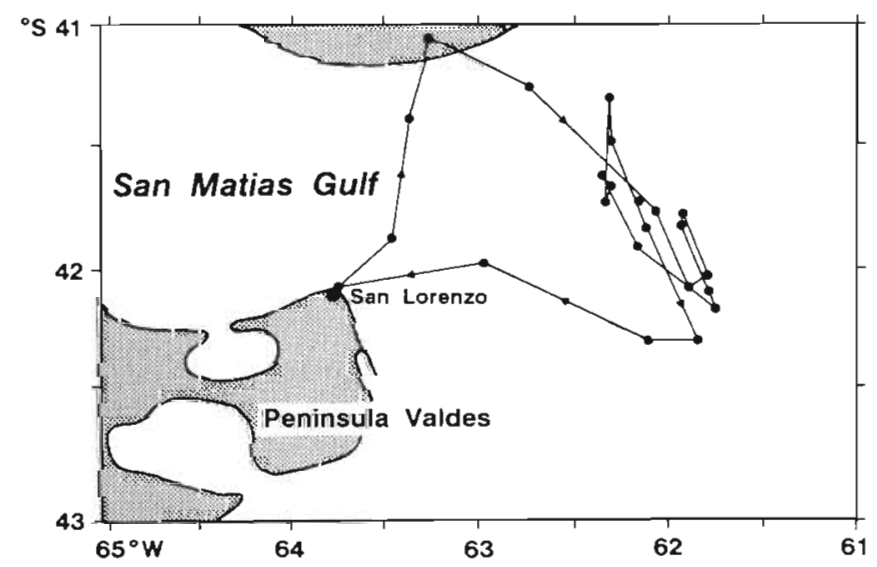

Fig. 1. Route taken by a female Magellanic penguin during a foraging period at sea during the incubation phase of the breeding cycle. Each dot indicates a positional fix corresponding to midday or midnight. The fix on land to the north in the initial period of the foraging trip indicates the potential degree of positional error since the bird was actually at sea at this time 


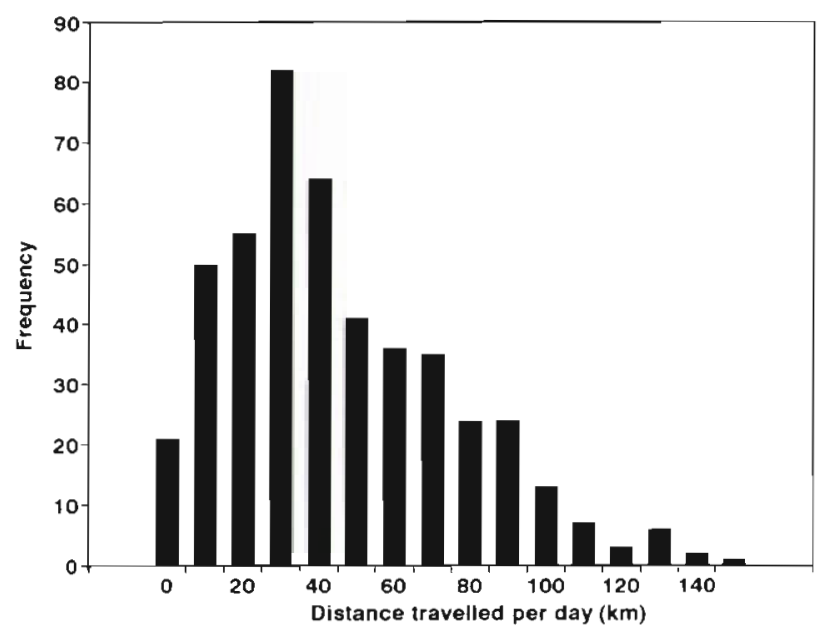

Fig. 2. Frequency distribution of the distance travelled per day by 10 foraging Magellanic penguins during the incubation phase of the breeding cycle

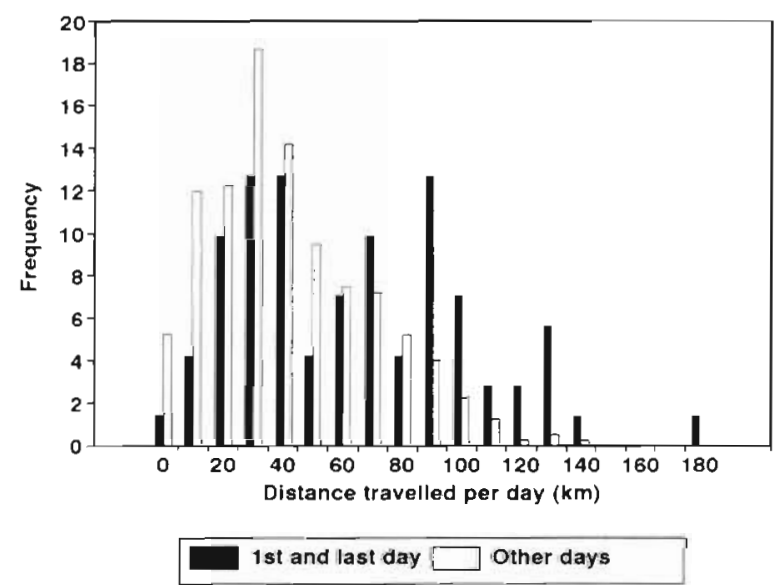

Fig. 3. Frequency distribution of the distance travelled per day by 10 foraging Magellanic penguins during the incubation phase of the breeding cycle. The distributions have been split in 2 consisting of data derived only from the first and last days of the foraging trip $(\mathrm{N}=71)$ and data from all other days $(\mathrm{N}=402)$

where they remained relatively stationary for a number of days before returning to the colony following a straight line course. Overall, the mean distance travelled per day was $50.2 \mathrm{~km}$ (SD 31.4, $\mathrm{n}=473$ ), but the frequency distribution of distance travelled per day was skewed and the mode was $35 \mathrm{~km}$ (Fig. 2). This skewed distribution was partially due to the fact that birds travelled significantly further on the first and last days of the foraging trip $(x=70.4, \mathrm{SD} 42.1, \mathrm{n}=71)$ than on other days $(x=46.5$, SD 27.6, $n=402)(t=6.15, p<$ 0.01) (Fig. 3).

The locality most frequented by foraging penguins occurred some $120 \mathrm{~km}$ east of the colony in water

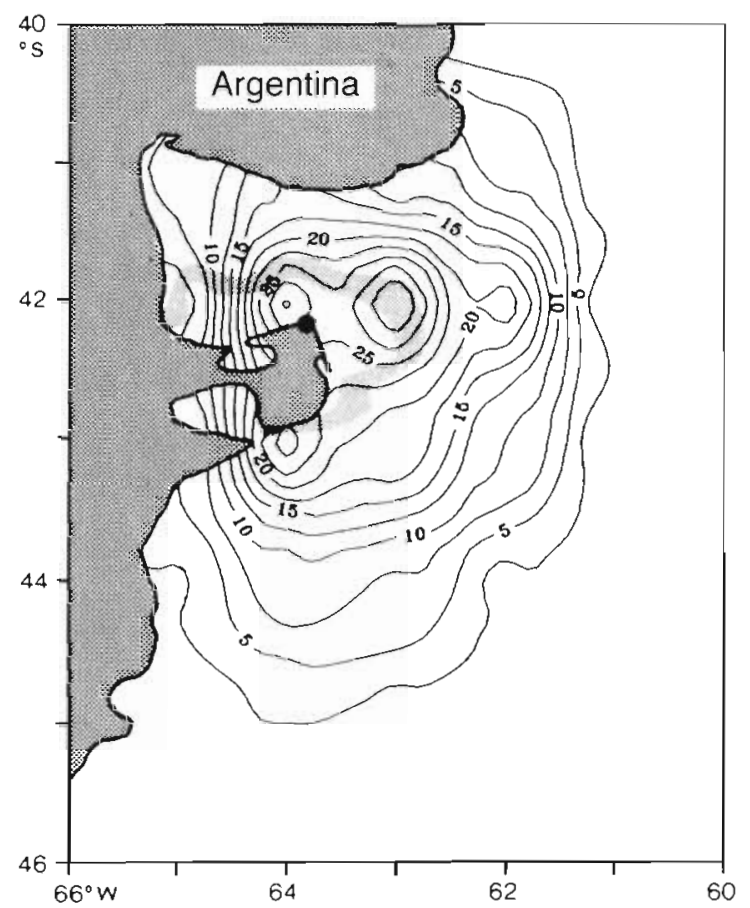

Fig. 4. Contour map showing distribution of foraging trips by 10 Magellanic penguins during the incubation phase of the breeding cycle. Lines are contours corresponding to the number of bird days per degree quadrat. Contour intervals are 2.5 bird days per degree quadrat. The shaded area shows the boundaries of a frontal system (data from Carreto et al. 1986) and the dot indicates the location of the breeding colony at San Lorenzo

ca $80 \mathrm{~m}$ deep where bird densities reached 32 bird days per degree ${ }^{2}$ (a degree ${ }^{2}$ at the given latitudes corresponds to a surface area of ca $9200 \mathrm{~km}^{2}$ ) (Fig. 4). However, 2 other minor peaks in bird density occurred, one immediately south of Peninsula Valdes and another ca $35 \mathrm{~km}$ west of the colony (Fig. 4). Overall, bird densities were high $\left(20\right.$ bird days per degree ${ }^{2}$ or higher) within $140 \mathrm{~km}$ of the colony, dropping off fairly rapidly at distances exceeding $160 \mathrm{~km}$ (Fig. 4). Mean distance to the colony was $117.3 \mathrm{~km}$ (SD 59.4, $\mathrm{n}=473$ ) although the frequency distribution of distance to the colony was slightly skewed (Fig. 5), with a number of birds ex-ceeding $200 \mathrm{~km}$. Maximum distance to the colony was calculated to be $303 \mathrm{~km}$. There was no evidence to suggest that birds which were absent from the nest for longer periods travelled further from the colony $(F=0.28, \mathrm{n}=14, \mathrm{p}>0.05)$.

\section{DISCUSSION}

The foraging pattern of Magellanic penguins as determined by the GLS units conforms closely to that documented for other penguins as well as other 


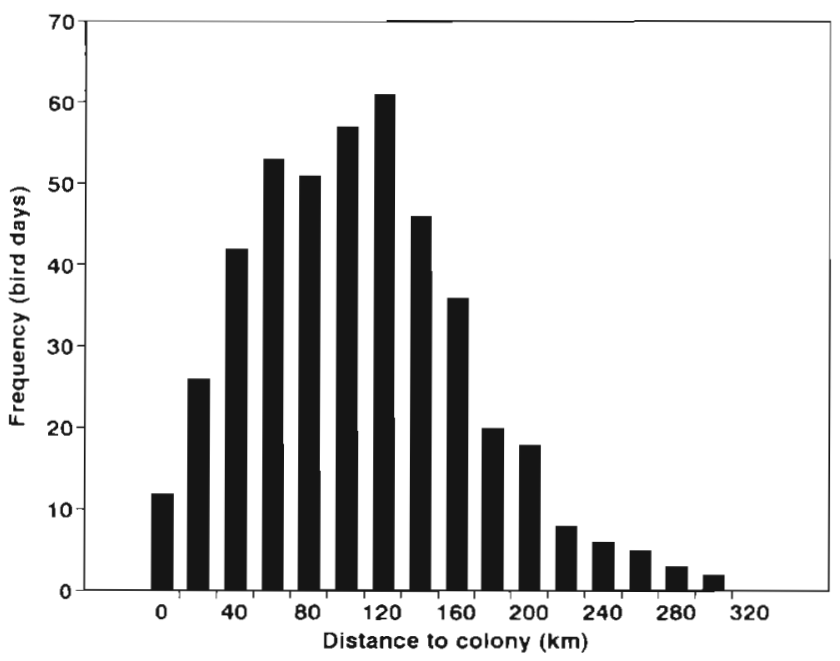

Fig. 5. Frequency distribution of the number of bird days as a function of distance to the colony for foraging Magellanic penguins during the incubation phase of the breeding cycle

seabirds. Wilson (1995) documents that during short foraging trips, (less than 1 d) while provisioning for chicks, pygoscelid penguins generally execute a looping course which consists of some meandering away from the colony to a foraging area, whereupon the swim trajectory becomes much less directional for a time before birds return to the colony in a more or less straight line. The same appears true for king penguins Aptenodytes patagonicus, absent for between 7 and $32 \mathrm{~d}$ while foraging for their chicks (Jouventin et al. 1994). Jouventin \& Weimerskirch (1990) used satellite tracking to show that wandering albatrosses Diomedea exulans also execute similar looping courses during foraging trips. Such looping courses generally display a rapid departure from, and return to, the colony before prey searching behaviour is apparent. This also conforms with our results and indicates that foraging in the vicinity of the breeding ground is likely to be less profitable than further afield. If this is the case in all individuals, it would seem that although local prey densities may be reduced, this is not an effect of predatorinduced prey depletion but is rather a simple case of unsuitable conditions for the prey species in the vicinity of the breeding site. Even after taking this into account, however, our results indicate no evidence for prey depletion near the colony since birds absent from the colony for longer do not necessarily forage at greater distances as would be predicted. There are 2 possible explanations for this. One is that the flux of prey through the foraging area is so high that birds cannot deplete resources. Ultimately, whether a halo of prey depletion occurs around a seabird breeding colony will depend on the rate at which birds remove the prey from the area and the rate at which the prey are renewed
(Springer et al. 1984, Springer \& Roseneau 1985). In species that feed on benthic prey, depletion is much more likely to occur since replacement only occurs as a result of reproduction or slow immigration (cf. Birt et al. 1987). Pelagic prey may move through areas quickly so that resources in one spot are continuously renewed. Magellanic penguins feed on pelagic prey such as silversides Atherina spp. and squid Loligo spp. (e.g. Scolaro \& Badano 1986) and it would appear that the numbers of birds breeding at San Lorenzo are not high enough to counteract this flux.

The other reason for apparent lack of a relationship between time absent and foraging distance from the colony is that prey density may not be homogenous, there being particular areas where densities are higher. If these areas are accessible within the normal time absent from the nest, and if such areas cannot be depleted, it is to be expected that birds move into these regions. Whether this is the case or not can be examined by comparing areas available to the birds during the different stages of breeding. During the chickrearing phase of the breeding cycle, foraging trips are about $24 \mathrm{~h}$ (Scolaro et al. in press). The 95\% quantile regarding the distance that birds can travel per day on the first and last day of the foraging trip indicates that birds can travel a maximum of $120 \mathrm{~km}$ during this time (see Fig. 3) so that the maximum foraging range would be half that, or $60 \mathrm{~km}$. A more realistic figure, however, would be half this because foraging birds do not travel directly away from the colony (Wilson et al. 1989, Wilson \& Wilson 1990). If we assume that penguins breeding at San Lorenzo have an area of sea available to them corresponding to $270^{\circ}$ of a circle (see Fig. 4) whose radius is $30 \mathrm{~km}$, then chick-rearing birds can exploit an area of some $2120 \mathrm{~km}^{2}$. Assuming that the colony at San Lorenzo consists of some 40000 breeding birds, of which half will be foraging at any one time, then there will be an average density of ca 9.2 birds $\mathrm{km}^{-2}$ within $30 \mathrm{~km}$ of San Lorenzo during chick rearing.

Penguins foraging during the incubation period have a much greater range. If we take the contour line corresponding to the $99 \%$ quantile as this range limit, an area of approximately $135640 \mathrm{~km}^{2}$ is available to these birds. Assuming that the area is not used by any other penguins, then the average penguin density within this area will be about 0.15 birds $\mathrm{km}^{-2}$. However, penguin density is not uniform within this area. We can convert the contour lines plotted in Fig. 4 into numbers of individuals (per unit time) by dividing the total number of birds likely in the area (20000) by the total number of recorded bird days at sea from our study (220). At its most dense part, the peak in penguin density to the east of San Lorenzo thus amounts to 2900 birds over an area of ca $430 \mathrm{~km}^{2}$ which corresponds to a bird 
density of approximately 7.8 birds $\mathrm{km}^{-2}$. This figure is similar to that considered as occurring within the foraging radius of chick-rearing birds when range restrictions imposed by the frequency of brood food requirements are extreme. It would thus seem that Magellanic penguins breeding at San Lorenzo do not experience penguin-induced prey depletion in the vicinity of the colony, at least during the incubation period. Rather, the extended foraging periods of the birds at this time, compared to later in the breeding cycle, allow the penguins to move to more distant areas where prey densities may be higher for reasons other than prey depletion. Although data on the oceanography of the area are scarce, there is a frontal system with enhanced productivity (Carreto et al. 1986) that coincides with the major peak in penguin density (Fig. 4). If this productivity also leads to enhanced pelagic fish density, it could be reason enough for penguins to aggregate in this area.

Acknowledgements. This study was funded by the Deutsche Forschungsgemeinschaft with a grant to $D$. Adelung and the VW Stiftung. We are grateful to G. Dorn and U. Lenz tor technical help with device construction.

\section{LITERATURE CITED}

Bannasch R, Wilson RP, Culik B (1994) Hydrodynamic aspects of design and attchment of a back-mounted device in penguins. J exp Biol 194:83-96

Birt VL, Birt TP, Goulet D, Cairns DK, Montevecchi WA (1987) Ashmole's halo: direct evidence for prey depletion by a seabird. Mar Ecol Prog Ser 40:205-208

Boersma PD (1988) Magellanic penguins of Patagonia. Spheniscid Penguin Newsletter 1:2-3

Boersma PD, Stokes DL, Yorio PM (1990) Reproductive variability and historical change of Magellanic penguins (Spheniscus magellanicus) at Punta Tombo, Argentina. In: Darby J, Davis LS (eds) Penguin biology. Academic Press, Orlando, FL, p 15-43

Carreto JI, Benavides HR, Negri RM, Glorioso PD (1986) Toxic red-tide in the Argentine Sea. Phytoplankton distribution and survival of the toxic dinoflagellate Gonyaulax excavata in a frontal area. J Plankton Res 8:15 - 28

Hill RD (1993) Theory of geolocation by light levels In: Ie Boeuf BJ, Laws RM (eds) Elephant seals: population ecology, behavior, and physiology. University of California Press, Berkeley, p 227-236

Hunt GL, Eppley ZA, Schneider DC (1986) Reproductive performance of seabirds: the importance of population and colony size. Auk 103:306-317

Jouventin P, Capdeville D, Cuenot-Chaillet F, Boiteau C (1994) Exploitation of pelagic resources by a non-flying

This article was submitted to the editor seabird: satellite tracking of the king penguin throughout the breeding cycle. Mar Ecol Prog Ser 106:11-19

Jouventin P, Weimerskirch $H$ (1990) Satellite tracking of wandering albatrosses. Nature 343:746-748

Orians GH, Pearson NE (1979) On the theory of central place foraging. In: Horn DJ, Mitchell R, Stair GR (eds) Analysis of ecological systems. Ohio State University Press, Columbus, $p$ 155-177

Pearson TH (1968) The feeding biology of seabird species breeding on the Farne Islands. J Anim Ecol 37:521-532

Scolaro JA (1984) Timing of nest relief during incubation and guard stage period of chicks in Magellanic penguins (Spheniscus magellanicus). Hist Nat 4:281-284

Scolaro JA (1986) La conservación del Pingüino de Magellanes: un problema de conflicto de intereses que requiere de argumentos cientificos. An Mus Hist Nat Valparaiso 17. $113-119$

Scolaro JA, Badano LA (1986) Diet of the Magellanic Penguin Spheniscus magellanicus during the chick-rearing period at Punta Clara, Argentina. Cormorant 13:91-97

Scolaro JA, Hall MA, Ximenez IM (1983) The Magellanic Penguin (Spheniscus magellanicus) sexing adults by discriminant analysis of morphometric characters. Auk $100: 221-224$

Scolaro JA, Laurenti S, Gallelli H (in press) El area de forrajeo como reserva en una colonia del Pingüino de Magallanes. Actas del II Congreso Internacional de Gestión en Recursos Naturales, Pucón, Chile 1993. Universidad Austral de Chile, Valdivia

Springer AM, Roseneau DG (1985) Copepod-based food webs: auklets and oceanography in the Bering Sea. Mar Ecol Prog Ser 21:229-237

Springer AM, Roseneau DG, Murphy EC, Springer MI (1984) Environmental controls of marine food webs: food habits of seabirds in the eastern Chukchi Sea. Can J Fish Aquat Sci 41:1202-1215

Weimerskirch H, Bartle J A, Jouventin P. Stahl JC (1988) Foraging range and partitioning of feeding zones in three species of southern albatrosses. Condor 90:214-219

Williams TD (1995) The penguins. Oxford University Press, Oxford

Wilson RP (1995) Foraging ecology. In: Williams TD (ed) The penguins. Oxford University Press, Oxford p 81-106

Wilson RP, Ducamp JJ, Rees G, Culik BM, Niekamp K (1992) Estimation of location: global coverage using light intensity. In: Priede IM, Swift SM, (eds) Wildlife telemetry: remote monitoring and tracking of animals. Ellis Horwood, Chichester, p 131-134

Wilson RP, Nagy KA, Obst B (1989) Foraging ranges of penguins. Polar Rec 25:303-307

Wilson RP, Wilson MP (1989) Tape: a package attachment technique for penguins. Wildl Soc Bull 17:77-79

Wilson RP, Wilson, MP (1990) The foraging ecology of breeding Spheniscus penguins. In: Davis LS, Darby JT (eds) Penguin biology. Academic Press, San Diego, CA, p $181-206$

Yorio P, Boersma PD (1994) Causes of nest desertion during incubation in the Magellanic Pengum (Spheniscus magellanicus). Condor 96:1076-1083

Manuscript first received: April 25, 1995

Revised version accepted: June 6, 1995 